\title{
An Investigation of Degradation of Mechanical Behaviour of Prestressing Strands Subjected to Chloride Attacking
}

\author{
Zhao-Hui Lu \\ National Engineering Laboratory for High Speed Railway Construction, School of Civil Engineering, \\ Central South University, 22 Shaoshannan Road, Changsha 410075, China
}

Fan Li

School of Civil Engineering, Central South University, 22 Shaoshannan Road, Changsha 410075, China

Yan-Gang Zhao

School of Civil Engineering, Central South University, 22 Shaoshannan Road, Changsha 410075, China

Department of Architecture and Building Engineering, Kanagawa University, 3-27-1 Rokkakubashi, Kanagawa-ku, Yokohama 221-8686, Japan

\begin{abstract}
Corrosion of reinforcing and prestressing steel due to chloride contamination is one of the primary causes of deterioration of concrete structures. A review of published literatures shows that the research on the deterioration of mechanical properties of reinforcing steel is more than that on prestressing strands, even though the corrosion of prestressing strands may trigger structural collapse without warnings due to higher stress levels in the steel. This paper aims to investigate the degradation of mechanical behaviour of corroded prestressing strands. Details of a comprehensive experiment designed to examine the mechanical behaviour of corroded prestressing strands in concrete structural members are presented. A micromechanical damage model for failure mechanism of corroded prestressing strands is proposed, and a model for damage factor is derived. Based on these models, a constitutive model for corroded prestressing strands is developed and verified with test results. It is found in the paper that both the strength and ductility of corroded prestressing strands decrease with the increase of corrosion and that the hemispherical model for the pit shape is more appropriate for the prediction of strength reduction of corroded prestressing strands. The paper concludes that the constitutive model developed in the paper can be used to predict the mechanical behaviour of corroded prestressing strands accurately, paving the way for the assessment of corrosion-induced flexural failure of prestressed concrete structures.
\end{abstract}

\section{INTRODUCTION}

Corrosion of reinforcing and prestressing steel due to chloride contamination is one of the primary causes of deterioration of concrete structures. Research on the influence of steel corrosion on the global behavior of concrete structures has been both intensive and extensive in the past few decades (ACl 365.1R, 2002; ACI 222. 2R-01, 2001). However, studies have focused more on reinforced concrete $(R C)$ structures than on prestressed concrete (PC) structures, even though PC structures have been used in many construction and are increasingly being used in new constructions that are particularly sensitive to steel corrosion (Li \& Yuan, 2013; Rinaldi, Imperatore, \& Valente, 2010).

In prestressed structures, the potential consequences of steel corrosion are much more serious than in reinforced concrete, since prestressing strands are subjected to high mechanical stresses, and consequently the combination of corrosion-induced sectional reductions and notch effects can be fatal for structural safety (ACI 222. 2R-01, 2001; Bergsma, Boon, \& Etienne, 1977; CUR-Netherland Committee for Concrete Research, 1977). Furthermore, corrosion in prestressing steel is rather underhand, because it does not produce rust in such amounts to cause concrete cracking corrosion and the structural collapse may be sudden (Hover, 1996). The collapse of Ynysy-gwas Bridge in Port Talbot, UK (see Figure 1) is the most typical structural collapse caused by corrosion of prestressing steel strands under its own weight without warnings, indicating a considerable reduction of its load carrying capacity due to the reduction of cross-sectional area of corroded prestressing strands (Woodward \& Williams, 1988). 


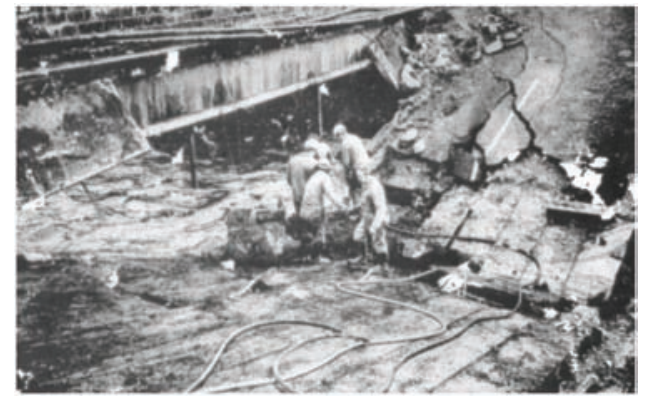

Figure 1. Collapse of Ynys-y-gwas Bridge in Port Talbot.

Both experimental results and field experiences suggest that a large proportion of structural damages in PC structures, in particular collapses, are caused by pitting corrosion of prestressing steels but insufficient research has been undertaken to study the characteristics of pitting corrosion in PC structures.

In this paper, the degradation of mechanical behaviour of corroded prestressing strands has been investigated. A micromechanical damage model for failure mechanism of corroded prestressing strands is proposed, and a model for damage factor is derived. Based on these models, a constitutive model for corroded prestressing strands is developed and verified with experimental results. The paper concludes that the constitutive model developed in the paper can be used to predict the mechanical behaviour of corroded prestressing strands accurately, paving the way for the assessment of corrosion-induced flexural failure of prestressed concrete structures.

\section{EXPERIMENTAL PROGRAM}

\subsection{Design of test specimens}

A total of 14 sets of prestressing strands were manufactured as specimens. They consist of 2 sets of un-corroded control specimens and 12 sets of corroded specimens embedded in concrete. Strands were embedded in seven sets of concrete specimens, which were cast with a same cross-section of $150 \mathrm{~mm} \times 60 \mathrm{~mm} \times 250 \mathrm{~mm}$ and a concrete cover of $15 \mathrm{~mm}$, as shown in Figure 2. Details of test specimens are shown in Table 1.

The concrete mixture for test specimens in Figure 3(b) was composed of ordinary Portland cement, tap

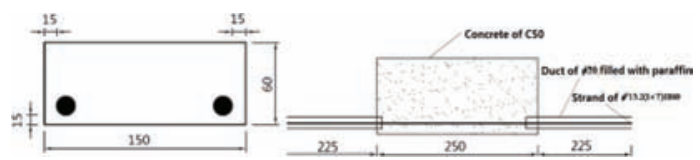

Figure 2. Detail of test specimens.
Table 1. Details of test specimens.

\begin{tabular}{cccc}
\hline Groups & $\begin{array}{c}\text { Current intensity } \\
\left(\mathbf{m A} / \mathbf{c m}^{2}\right)\end{array}$ & $\begin{array}{c}\text { Corrosion } \\
\text { time }\end{array}$ & $\begin{array}{c}\text { Target } \\
\text { corrosion } \\
\text { rate }(\%)\end{array}$ \\
\hline LS1 & 1 & $28 \mathrm{~h}$ (1 day) & 1 \\
LS2 & 1 & $112 \mathrm{~h}$ (5 days) & 4 \\
LS3 & 1 & $196 \mathrm{~h}$ (8 days) & 7 \\
LS4 & 1 & $280 \mathrm{~h}$ (12 days) & 10 \\
LS5 & 1 & $364 \mathrm{~h}$ (15 days) & 13 \\
LS6 & 1 & 448 h (19 days) & 16 \\
LS7 & 1 & 532 h (22 days) & 19 \\
LS0 & No & 0 & 0 \\
\hline
\end{tabular}

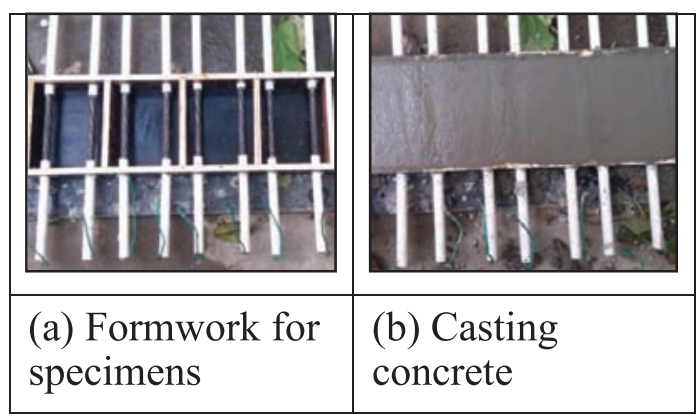

Figure 3. Preparation of test specimens.

water, natural river sand as fine aggregates and crushed gravels with a maximum size of $20 \mathrm{~mm}$ as coarse aggregates. The mix design is given in Table 2. To ensure quality, all test specimens were cast in laboratory and were demolded 3 days after casting. They were all placed outdoor for standard curing until the average concrete cube strength reached $55.7 \mathrm{MPa}$.

\subsection{Method of corrosion acceleration}

It is acknowledged that strands corrosion in concrete structures under natural environments could take a long time to have significant influence on mechanical behaviours of both the strands and structures. Meanwhile, corroded strands collected from aged structures are not always available for experiments. Therefore, an electrochemical acceleration technique was adopted to simulate corrosion within a short term. To avoid the deficiencies of uniform corrosion and

Table 2. Composition of concrete mixture.

\begin{tabular}{ccccc}
\hline $\begin{array}{c}\text { Concrete } \\
\text { class }\end{array}$ & $\begin{array}{c}\text { Cement } \\
\mathbf{( k g )}\end{array}$ & $\begin{array}{c}\text { Fine } \\
\text { aggregate } \\
\mathbf{( k g )}\end{array}$ & $\begin{array}{c}\text { Coarse } \\
\text { aggregate } \\
\mathbf{( k g )}\end{array}$ & $\begin{array}{c}\text { Water } \\
\mathbf{( k g )}\end{array}$ \\
\hline C50 & 343 & 686 & 1072 & 147 \\
\hline
\end{tabular}


washing away of corrosion products by full immersion in a solution of sodium chloride as published in the literature (Lee \& Cho, 2009), alternate wetting and drying cycles were used to accelerate the ingression of chlorides. Chlorides ingression was achieved by wrapping test specimens with sponge which was saturated with solution of $5 \%$ sodium chloride by weight (behaved as electrolyte) after removing the formwork. The solution was sprinkled on the sponge every second day during the test to ensure the full contact between specimens and solution (in wetting period) or oxygen (in drying period), respectively. A stainless steel plate was placed underneath the sponge being connected to the negative terminal of DC, while the strands embedded in concrete were connected to the positive terminal. Meanwhile, an ammeter and a potentiometer were used to adjust and monitor the current intensity to a constant of $1 \mathrm{~mA} / \mathrm{cm}^{2}$. Different corrosion time was employed to achieve various degrees of corrosion with theoretical target corrosion rate $\eta$ to be determined as follows (Huo, 2007):

$$
\eta=1-\left(1-\frac{i \cdot t_{c}}{13441 d_{0}}\right)^{2}
$$

where $i$ is the current density, $t_{c}$ is the conduction time of the current, and $d_{0}$ is the nominal diameter of strands without corrosion.

\subsection{Tensile test}

A total of 12 sets of corroded strands were retrieved from the broken specimens. The strands were all processed manually according to the requirements of test specification. They were cleaned with hydrochloric acid, calcium hydroxide, and tap water, to wash away the salt deposits or corrosion products. Then, they were kept in a drier for $4 \mathrm{~h}$ before tensile test. The mechanical tensile tests on strands were conducted with a universal testing machine, as shown in Figure 4. Each strand was labelled with a plastic tag to distinguish different corrosion rates. During the tensile tests, an extensometer with an effective range of $50 \mathrm{~mm}$ was mounted on specimens over the most likely failure zone, as indicated by most severe corrosion. At the beginning, approximately $100 \mathrm{MPa}$ of preloading was applied to the specimens to eliminate the slip between test strands and anchorage. The specimens were then loaded up to $80 \%$ of ultimate strength at a constant rate of $0.2 \mathrm{kN} / \mathrm{s}$, in order to avoid the effect of impact load and/or the non-quasi-static load. The applied load and the deformation within the gauge length during the tension experiments were recorded using an automatic data logging system. The uniform elongation was calculated based on the measurement from tested specimens.

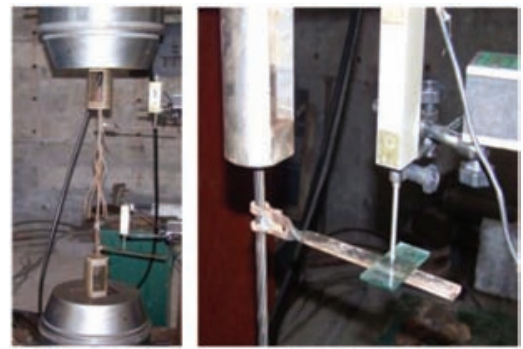

Figure 4. Tensile tests of corroded strands

\section{TEST RESULTS AND ANALYSIS}

\subsection{Degree of corrosion}

Concrete specimens were broken open after corrosion from which strands were retrieved. It can be seen from strands that the localized pitting corrosion is the predominant corrosion pattern. It is of interest to see that the pitting corrosion occurs along the longitudinal direction, which approximately characterizes the corrosion in real structures. To further distinguish the corrosion between different specimens quantitatively, a maximum degree of corrosion, denoted as $\eta_{\text {smax }}$, for all corroded strands is introduced as follows:

$$
\eta_{s \max }=\frac{A_{0}-A_{\min }}{A_{0}} \times 100 \%=\frac{d_{0}^{2}-d_{\text {min }}^{2}}{d_{0}^{2}} \times 100 \%
$$

where $A_{0}, d_{0}$ are the nominal cross-sectional areas and diameters of strands before corrosion, whereas $A_{\min }, d_{\min }$ are the minimum cross-sectional areas and diameters after corrosion.

Regard strands as a reinforcement, which crosssectional area is equal to strands. Based on above assumption for a strand, we can obtain the minimum cross-sectional area of corroded strands [regarding strand of $\phi^{\mathrm{s}} 15.2(1 \times 7) 1860$ as a reinforcement which $d_{0}$ is $13.3 \mathrm{~mm}$ ]. Equation (2) can truly represent the stress concentration at the minimum cross-section of corroded strands. Meanwhile, observations of the fractured sections of corroded strands demonstrate that the failure usually occurred at the locations with minimum cross-sectional area. And corrosion shape of corroded strands is shown in Figure 5.

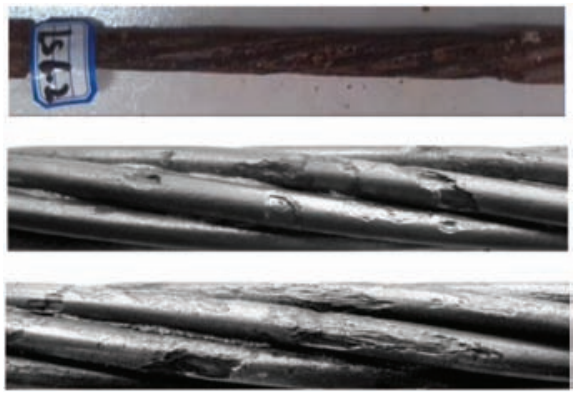

Figure 5. Corrosion shape of corroded strands 


\subsection{Stress-strain relation}

To obtain a clear understanding of the effect of corrosion on mechanical properties of strands, the stress-strain $(\sigma-\varepsilon)$ curves for different corrosion rates within the gauge length were recorded. For comparison between different corrosion rates of strands, all representative $\sigma-\varepsilon$ curves have been shown in Figure 6. It can be seen clearly from figures that corrosion causes significant degradation in mechanical behaviour, which was also found in previous investigations (Li, Yuan, Du, \& Ma, 2009; Luo \& Li, 2008; Zheng, Ou, \& An, 2005). More specifically,

(1) the strength of corroded strands decreases sharply with the increase of corrosion rate. For example, compared with the $\sigma-\varepsilon$ curves of intact strand (corrosion rate $=0 \%$ ) in Figure 6 , the strength of corroded strands reduced to $19.79 \%$ when the corrosion rate increased to $6.30 \%$. Moreover, it is astonishing to see that at the corrosion rate of $20.40 \%$, only $38.1 \%$ of strength remained. The strength degradation is most likely due to the stress concentration caused by pitting corrosion and/or eccentric tension due to asymmetric corrosion distribution.

(2) the reductions in ductility (characterized by uniform elongation) with the increase of corrosion rate can be observed obviously. These results are in good agreement with those of previous studies (Li et al., 2009). As can be seen from Figure 6, both the yielding plateau and the strain hardening region of the $\sigma-\varepsilon$ curves for corroded strands are smaller with the increase of corrosion rate and even disappeared when the corrosion rate is larger than $8 \%$. This may be due to the corrosioninduced change of metallic lattice structure, including the accumulation of dislocated crystal grains and the stress concentration on a single crystal grain, which may result in the change of failure mode from ductile with intergranular fracture to brittle with transcrystalline rupture when the corrosion rate is larger than $8 \%$. It is in

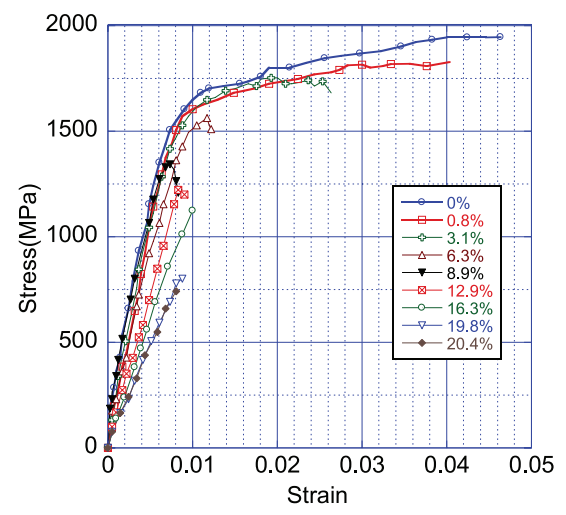

Figure 6. Stress-strain curves of corroded strands. this regard that a critical corrosion rate denoted as $\eta_{\text {scr }}$ is introduced and set at $8 \%$, i.e., $\eta_{\text {scr }}=8 \%$.

For comparison of mechanical properties between corroded and non-corroded strands, it is necessary to have the $\sigma-\varepsilon$ curves for non-corroded strands, which were also obtained from the experiment and are shown in Figure 7(a). Based on the characteristics of this curve, a bi-linear approximation can be made and shown in Figure 7(b). By analysis of data for key parameters governing these curves, a mathematical expression can be established as follows:

$$
\sigma=\left\{\begin{array}{lr}
E_{s} \cdot \varepsilon & \varepsilon \leq \varepsilon_{y}=0.85 f_{u} / E_{s} \\
0.85 f_{u}+\frac{\varepsilon-\varepsilon_{y}}{\varepsilon_{u}-\varepsilon_{y}} \cdot 0.15 f_{u} & 0.85 f_{u} / E_{s}<\varepsilon \leq \varepsilon_{u}
\end{array}\right.
$$

where $E_{s}$ is the elastic modulus, $f_{u}$ is the ultimate strength, $\varepsilon_{y}$ is the strain corresponding to $0.85 f_{u}$, $\varepsilon_{u}$ is the ultimate strain. Specific values of all these characteristic parameters are summarized in Table 3. Equation (3) can be used for comparison with that of corroded strand. Similar models have also been proposed in the literature (Zeng, Gu, Zhang, \& Huang, 2010).
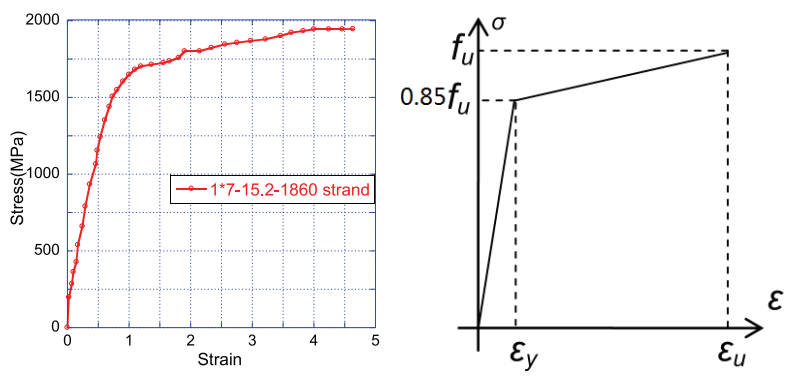

(a) Stress-strain curve of (b) simplified model of intact strand stress-strain curve

Figure 7. Model of stress-strain relationship.

Table 3. Mechanical properties of intact strands.

\begin{tabular}{cccccc}
\hline Specimens & $\boldsymbol{E}_{\boldsymbol{s}}$ & $\begin{array}{c}\boldsymbol{f}_{y}=\mathbf{0 . 8 5 \boldsymbol { f } _ { u }} \\
\mathbf{( M P a )}\end{array}$ & $\boldsymbol{\varepsilon}_{y}=\mathbf{0 . 8 5 \boldsymbol { f } _ { u } / E _ { \boldsymbol { s } }}$ & $\begin{array}{c}\boldsymbol{f}_{u} \\
(\mathrm{MPa})\end{array}$ & $\boldsymbol{\varepsilon}_{u}$ \\
\hline LS0 & $2.0 \mathrm{E}-05$ & 1657.5 & 0.0083 & 1950 & 0.05 \\
\hline
\end{tabular}

\section{MODELLING OF CORROSION-INDUCED DAMAGE}

\subsection{Damage model}

Inferring from the unit (spring) model for micromechanical damage developed for mechanical behaviour of concrete (Kandarpa, Kirkner, \& Spencer, 1996; Li, Lu, \& Zhang, 2003), a unit (spring) model for micromechanical damage is proposed here for theoretical analysis of the behaviour of corroded 
strands with the following assumptions. First, a strand consists of a series of damage units with the same characteristics and height. Each damage unit is composed of a row of identical springs with equal space and in parallel (see Figure 8). Second, the initiation and development of damage are only caused by macrocorrosion and stress. The initial microdefects incurred in the making process are neglected. Third, only one damage surface within a unit is considered and the damage factor (to be defined below) is deemed to be continuous in the process of tensile failure. Based on above assumptions, it is proposed that the damage unit consists of a row of springs with both ends fixed to a rigid plate, and an initial break of a spring indicates a microdamage caused by corrosion as shown in Figure 8(a). Therefore, the corroded strands can be modelled as a series of damage units as illustrated in Figure 8(b). Each spring has the stiffness $E_{i}$ and an area $d A_{i}$. Since it is assumed that all springs are fixed to the rigid plate at both ends, the stress released from a broken spring should be shared uniformly with the rest of them.

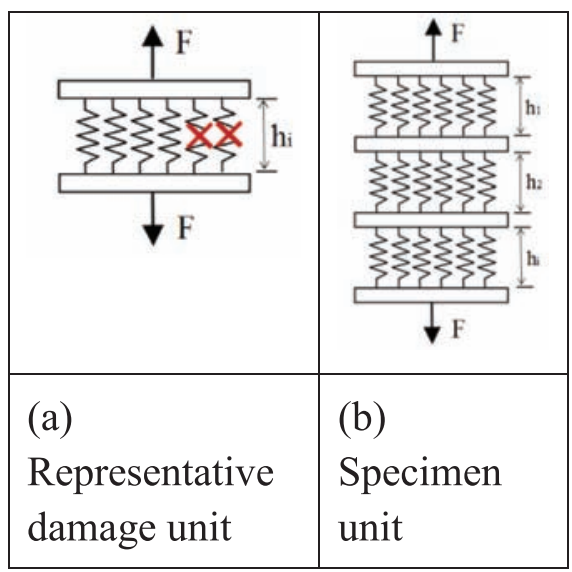

Figure 8. Model of micro-spring damage unit.

The failure process of a unit starts from an initial fracture of spring caused by corrosion. With the increase of stress towards fracture, the damage is developed and accumulated with further breaks of other springs due to the reduction of cross sectional area and hence sharp increase of strain. It is suggested that the effective area of a spring is 0 after its break, which indicates the presence of microvoids in the strand. Based on above assumptions for a representative unit, the loss of crosssectional area of a strand, denoted as $A_{p}(t)$, at time $t$ caused by corrosion can be determined by the following:

$$
A_{p}(t)=A_{0}-\sum_{i=1}^{n} H\left(d A_{i}-\Delta A_{i}\right) \cdot \Delta A_{i}
$$

in which, $A_{0}$ is the initial effective area of a representative unit before the development of damage; $\Delta A_{i}$ is the effective area of a single spring after damage, which is 0 when the spring is broken; $t$ is the corrosion time, which is measured from the initiation of corrosion and $H(x)$ is the Heaviside function which satisfies the following condition:

$$
H(x)= \begin{cases}1 & x \geq 0 \\ 0 & x<0\end{cases}
$$

The external force should be balanced with the resultant of internal forces of all springs within the linear elastic stage, when the unit is in quasistatic state during the whole mechanical test. Thus, the following relationship can be established with the parameters $E_{1}=E_{2}=\ldots=E_{i}=E_{s}$, according to the assumption of identical springs:

$$
\begin{aligned}
\sigma(\varepsilon) \cdot A_{0} & =F(\varepsilon)=E_{s} \cdot \varepsilon \cdot \sum_{i=1}^{n} H\left(d A_{i}-\Delta A_{i}\right) \cdot \Delta A_{i} \\
& =E_{s} \cdot \varepsilon \cdot\left[A_{0}-A_{p}(t)\right] \\
\sigma(\varepsilon) & =E_{s} \cdot \varepsilon \cdot \frac{\sum_{i=1}^{n} H\left(d A_{i}-\Delta A_{i}\right) \cdot \Delta A_{i}}{A_{0}} \\
& =E_{s} \cdot \mathcal{E} \cdot \frac{\left[A_{0}-A_{p}(t)\right]}{A_{0}}
\end{aligned}
$$

According to Figure 6, it is reasonable to assume that no damage occurs or develops under the cycle of loading and unloading during the linear elastic stage. Based on the classical damage theory of solid material and the homogeneous and isotropic properties of steel, an area damage factor is proposed, which is defined as the crosssectional area loss of the specimen, i.e., $D(t)=A_{p}(t) / A_{o}$

$$
D(t)=A_{p}(t) / A_{0}=1-\frac{1}{A_{0}} \cdot \sum_{i=1}^{n} H\left(d A_{i}-\Delta A_{i}\right) \cdot \Delta A_{i}
$$

\subsection{Area damage factor}

The hemispherical model is more applicable for strength prediction and hence is adopted in this paper for further analysis. Figure 9 illustrates the pit configuration of the hemispherical model (Val \& Melchers, 1997). Based on this model, the cross-sectional area of a pit, $A_{p}(t)$, in a reinforcing bar with a diameter $d_{0}$ after $t$ years of corrosion can be calculated as follows:

$$
A_{p}(t)= \begin{cases}A_{1}+A_{2} & p(t) \leq \frac{d_{0}}{\sqrt{2}} \\ \frac{\pi \cdot d_{0}^{2}}{4}-A_{1}+A_{2} & \frac{d_{0}}{\sqrt{2}}<p(t)<d_{0} \\ \frac{\pi \cdot d_{0}^{2}}{4} & p(t) \geq d_{0}\end{cases}
$$



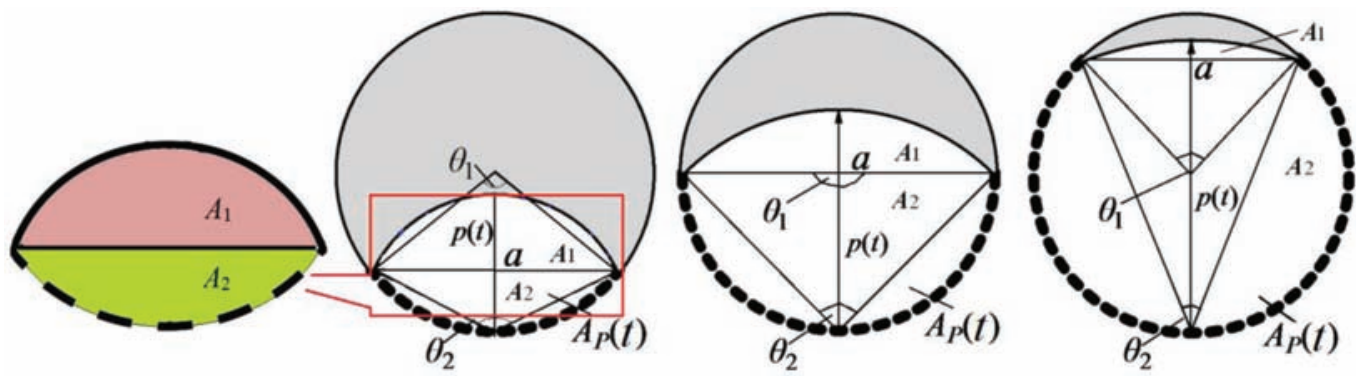

Figure 9. Pit configuration of the hemispherical model.

$$
\begin{aligned}
& A_{1}=\frac{1}{2}\left[\theta_{1}\left(\frac{d_{0}}{2}\right)^{2}-a\left|\frac{d_{0}}{2}-\frac{p(t)^{2}}{d_{0}}\right|\right] \\
& A_{2}=\frac{1}{2}\left[\theta_{2} \cdot p(t)^{2}-a \cdot \frac{p(t)^{2}}{d_{0}}\right] \\
& a=2 p(t) \sqrt{1-\left[\frac{p(t)}{d_{0}}\right]^{2}} \\
& \theta_{1}=2 \arcsin \left(\frac{a}{d_{0}}\right) \\
& \theta_{2}=2 \arcsin \left[\frac{a}{2 p(t)}\right]
\end{aligned}
$$

in which $A_{1}, A_{2}$ are the geometric parameters, corresponding to the area shaded in red and blue, respectively, as shown in Figure 9.

Usually, the extent of corrosion can be characterised by corrosion rate in terms of maximum cross-section loss $\eta_{\text {smax }}$, as defined in Eq. (2), which is calculated based on the cross-sectional area loss at the section of the most severe corrosion. However, it is very difficult to determine the location of the most severe corrosion and to measure the loss of strands cross-sectional area accurately. Therefore, for the application of test results to practical structures, a relationship between average corrosion rate $\eta_{s}$ to maximum cross-section loss $\eta_{\text {smax }}$ (Wang \& Zhong, 2005), and a relationship between the $\eta_{\text {smax }}$ to the maximum pitting depth $p(t)$, can be derived as follows.

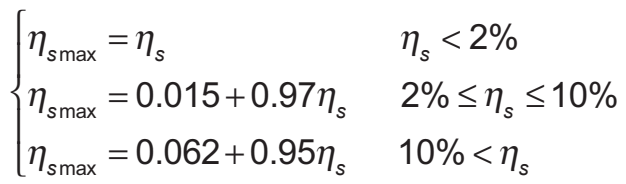

$$
\begin{aligned}
& \eta_{s \max }=\frac{d_{0}^{2}-d_{\min }^{2}}{d_{0}^{2}}=\frac{d_{0}^{2}-\left[d_{0}-0.5 p(t)\right]^{2}}{d_{0}^{2}} \\
& =\frac{p(t)}{d_{0}}-\left[\frac{0.5 p(t)}{d_{0}}\right]^{2}
\end{aligned}
$$

In order to express the $\eta_{\text {smax }}$ accurately, we find it is reasonable to assign $d_{\min }$ to $0.5 p(t)$ through comparative analysis. It is well known that $p(t)$ can be related to corrosion current density $i_{\text {corr }}$, Thus, the instantaneous pitting depth at time $t$ can be estimated (in millimeters) as follows:

$$
p(t)=0.0116 \cdot R \cdot \int_{0}^{t} i_{\text {corr }}(t) \cdot d t
$$

where $R$ denotes the ratio of the depth of pitting corrosion to the depth of uniform corrosion. Gonzalez, Andrade, Alonso, and Feliu (1995) suggest $R$ to be 4-8 with the inhomogeneity of corrosion. Considering the degree of randomness of $R$, the average value of $R$ can be set at $R=6$ hereinafter.

By substituting Eq. (12) into Eq. (9), the instantaneous pitting corrosion area of strands can be calculated as follows:

$$
A_{p}(t)= \begin{cases}\frac{1}{8} \theta_{1} \cdot d_{0}^{2}+\frac{1}{2} \theta_{2} \cdot p^{2}(t)-\frac{1}{4} a \cdot d_{0} & p(t) \leq \frac{d_{0}}{\sqrt{2}} \\ \frac{\pi \cdot d_{0}^{2}}{4}-\frac{1}{8} \theta_{1} \cdot d_{0}^{2}+\frac{1}{2} \theta_{2} \cdot p^{2}(t)-\frac{1}{4} a \cdot d_{0} & \frac{d_{0}}{\sqrt{2}}<p(t)<d_{0} \\ \frac{\pi \cdot d_{0}^{2}}{4} & p(t) \geq d_{0}\end{cases}
$$


From Eq. (8), the area damage factor, $D(t) \in[0,1]$, can be determined as follows.

$$
D(t)= \begin{cases}\frac{\theta_{1}}{2 \pi}+\frac{2 \theta_{2} \cdot p^{2}(t)}{\pi \cdot d_{0}^{2}}-\frac{a}{\pi \cdot d_{0}} & p(t) \leq \frac{d_{0}}{\sqrt{2}} \\ 1-\left[\frac{\theta_{1}}{2 \pi}-\frac{2 \theta_{2} \cdot p^{2}(t)}{\pi \cdot d_{0}^{2}}+\frac{a}{\pi \cdot d_{0}}\right] & \frac{d_{0}}{\sqrt{2}}<p(t) \leq d_{0}\end{cases}
$$

\section{DAMAGE CONSTITUTIVE MODEL OF CORRODED STRAND}

The $\sigma-\varepsilon$ relationship of corroded strands within the linear elastic stage can be simplified as follows by combining Eq. (7) with Eq. (8):

$$
\sigma(\varepsilon)=E_{s} \cdot \varepsilon \cdot[1-D(t)]
$$

As noted, Eq. (15) allows for loss of effective area due to corrosion as represented by area damage factor $D(t)$. Under the action of corrosion and stress, the new damage induced from stress and corrosion could be gradually emerged or developed, those damage factor caused by corrosion, referred to as corrosion damage factor (to be distinct from area damage factor), is introduced in terms of the deterioration of ultimate strain as $D(\varepsilon, t)=\varepsilon_{u}^{\prime} / \varepsilon_{u}$, the deterioration of ultimate stress as $D(f, t)=f_{u}^{\prime} / f_{u}$, the deterioration of modulus of elasticity as $D(E, t)=E_{s}^{\prime} / E_{s} D$, with $D(\varepsilon, t), D(f, t)$, $D(E, t) \in[0,1]$. Considering those damage factors, the constitutive model for corroded strands can be determined as follows:

When $\eta_{s} \leq \eta_{\text {scr }}$ :

$$
\sigma(\varepsilon)= \begin{cases}E_{s}^{\prime} \cdot \varepsilon \cdot[1-D(t)] & \varepsilon \leq \varepsilon_{y}^{\prime}=0.85 f_{u}^{\prime} / E_{s}^{\prime} \\ 0.85 f_{u}^{\prime}+\frac{0.15 f_{u}^{\prime}}{\varepsilon_{u}-\varepsilon_{y}} & \\ \cdot\left\{\varepsilon-[1-D(t)] \cdot \varepsilon_{y}^{\prime}\right\} & 0.85 f_{u}^{\prime} / E_{s}^{\prime}<\varepsilon \leq \varepsilon_{u}^{\prime}\end{cases}
$$

When $\eta_{s}>\eta_{s c r}$ :

$$
\sigma(\varepsilon)=E_{s}^{\prime} \cdot \varepsilon \cdot[1-D(t)]
$$

To verify Eq. (16), data produced from the experiment were used to calculate those corrosion damage factors, which are summarized in Table 4. Data produced from the experiment can also be used to calculate the area damage factor $D(t)$ with Eqs (8) and (10), which is, however, too complex to shown in the table. With four damage factors known, the theoretic constitutive relation for corroded strands can be determined with Eq. (16), the results are shown in Figure 10. Also shown in Figure 10 are $\sigma-\varepsilon$ curves

Table 4. Expressions of corrosion damage factor.

\begin{tabular}{lccc}
\hline $\begin{array}{l}\text { Corrosion damage } \\
\text { factor }\end{array}$ & $D(E, t)$ & $D(f, t)$ & $D(\varepsilon, t)$ \\
\hline Expressions & $1-1.8 f(D)$ & $1-2.8 f(D)$ & $\begin{array}{c}0.1+ \\
0.9 \exp [-20 f(D)]\end{array}$ \\
\hline
\end{tabular}

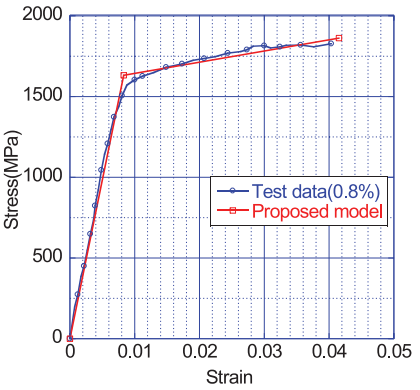

(a)

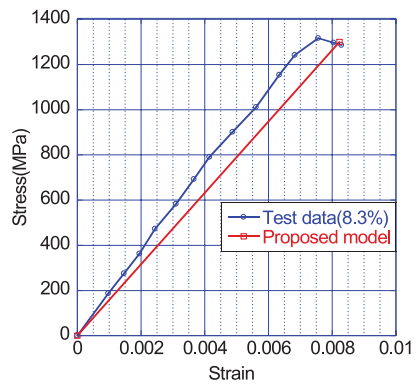

(d)

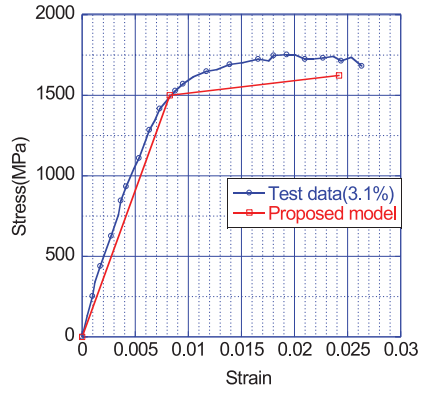

(b)

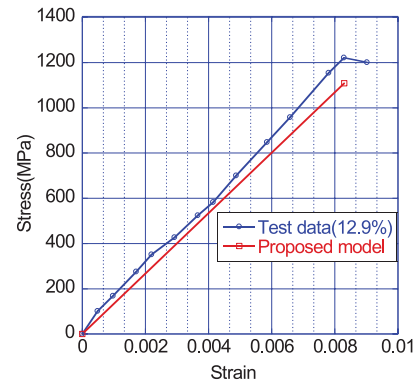

(e)

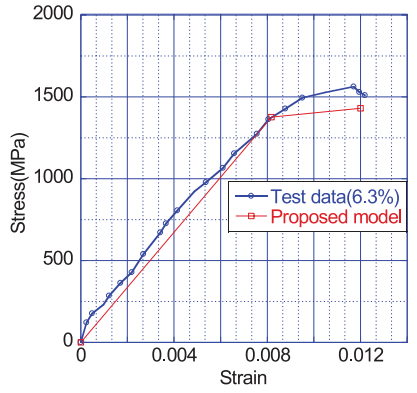

(c)

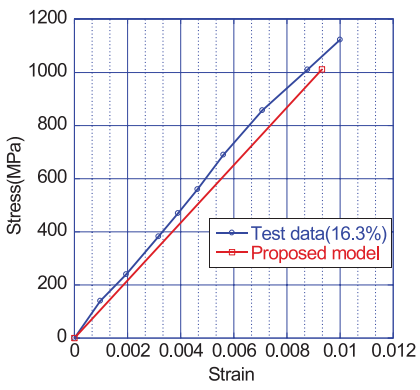

(f)

Figure 10. Comparison of theoretic constitutive model with test results. 
obtained from test data, i.e., extracted from Figure 6 and Figure 7. It can be seen from the comparison that the proposed constitutive model for corroded strands is in good agreement with the experimental results and hence Eq. (16) is verified.

\section{CONCLUSION}

The degradation of mechanical behaviour of corroded prestressing strands has been investigated thoroughly in this paper. Results produced from a comprehensive experiment on chloride-induced corrosion of prestressing strands in concrete members have been presented and analysed in details. A micromechanical damage model for failure mechanism of corroded prestressing strands has been proposed and a model for damage factor derived. Based on the proposed damage models, a constitutive model for corroded prestressing strands has been developed and verified with test results. It has been found in the paper that the strength of corroded prestressing strands decreases sharply with the increase of corrosion rate and that the hemispherical model for the pit shape is more appropriate for the prediction of strength reduction of corroded prestressing strands. It has also been found that the ductility of corroded prestressing strands reduces with the increase of corrosion rate in particular after the corrosion rate is larger than $8 \%$. It can be concluded that the constitutive model developed in the paper for corroded prestressing strands can be used to predict the mechanical behaviour of corroded prestressing strands accurately. With this developed model, the prediction and prevention of the flexural failure of prestressed concrete structures in corrosive environments have become possible.

\section{ACKNOWLEDGMENTS}

The research reported in this paper is partially supported by Grants from the Project of Innovationdriven Plan in Central South University, the National Natural Science Foundation of China (Grant No.: U1134209, 51422814, U1434204), the Ministry of Railways Science and Technology Research (Project No. 2013G003-A-3); meanwhile, the Program for Changjiang Scholars and Innovative Research Team in University (PCSIRT) (Grant No.IRT1296) is also gratefully acknowledged.

\section{REFERENCES}

ACI 222. 2R-01. (2001). Corrosion of prestressing steels. Detroit, MI: ACl.

ACI 365.1R. (2002). Service life prediction-state-ofthe-art report. ACI manual of concrete practicePart 5. Farmington Hills, MI: ACl.
Bergsma, F., Boon, J. W., \& Etienne, C. F. (1977). Endurance tests for determining the susceptibility of prestressing steel to hydrogen embrittlement. Heron, 22, 46.

CUR-Netherland Committee for Concrete Research. (1977). Cases of damage due to corrosion of prestressing steel (Report 49).

Gonzalez, J. A., Andrade, C., Alonso, C., \& Feliu, S. (1995). Comparison of rates of general corrosion and maximum pitting penetration on concrete embedded steel reinforcement. Cement and Concrete Research, 25(2), 257-264.

Hover, K. C. (1996). Special problems in evaluating the safety of concrete bridges and concrete bridge components. Construction and Building Materials, 10(1), 39-43.

Huo, Y. H. (2007). Research on shear capacity of simply supported concrete beam with corroded reinforcement (M.Sc. thesis). Nanchang, China: Nanchang University [in Chinese].

Kandarpa, S., Kirkner, D. J., \& Spencer, B. F. (1996). Stochastic damage model for brittle materials subjected to monotonic loading. Journal of Engineering Mechanics ASCE, 122(8), 788-795.

Lee, H. S., \& Cho, Y. S. (2009). Evaluation of the mechanical properties of steel reinforcement embedded in concrete specimen as a function of the degree of reinforcement corrosion. International Journal Fracture, 157(1-2), 81-88.

Li, F. M., \& Yuan, Y. S. (2013). Effects of corrosion on bond behavior between steel strand and concrete. Construction and Building Materials, 38(2), 413-422.

Li, F. M., Yuan, Y. S., Du, J. M., \& Ma, H. (2009). Deterioration of tensile behavior of steel strands corroded by chloride. Journal of Southeast University Natural Science Edition, 39(2), 340-344. [in Chinese].

Li, J., Lu, Z. H., \& Zhang, Q. Y. (2003). Research on the stochastic damage constitutive model of concrete materials. In: Proceedings of international conference on advances in concrete and structures, Xuzhou, China, 44-54.

Luo, X. Y., \& Li, Z. (2008). Mechanical performance of corroded unbonded prestressed steel stranded wires. Journal of the China Railway Society, 30(2), 108-112. [in Chinese].

Rinaldi, Z., Imperatore, S., \& Valente, C. (2010). Experimental evaluation of the flexural behavior of corroded P/C beams. Construction and Building Materials, 24(11), 2267-2278.

Val, D. V., \& Melchers, R. E. (1997). Reliability of deteriorating RC slab bridges. Journal of Structural Engineering-ASCE, 123(12), 1638-1644. 
Wang, X. H., \& Zhong, T. Y. (2005). Relation between the loss coefficient of the corroded rebar's cross-section in concrete and that of its weight. Research and Application of Building Materials, 1(4), 4-6. [in Chinese].

Woodward, R. J., \& Williams, F. W. (1988). Collapse of Ynys-y-Gwas bridge, West Glamorgan. Proceedings of the Institution of Civil Engineers Part 1, 84, 635-669.
Zeng, Y. H., Gu, X. L., Zhang, W. P., \& Huang, Q. H. (2010). Study on mechanical properties of corroded prestressed tendons. Journal of Building Materials, 13(2), 169-174. [in Chinese].

Zheng, Y. M., Ou, Y. P., \& An, L. (2005). Study on the test of mechanical properties of corroded steel bar embedded in concrete. Modern Technique of Communication, (6), 33-36. [in Chinese]. 